\title{
Interpretation of Kinetic Data for Reactions Involving Ions and Ion-Pairs using an Extended Conductance Equation
}

\author{
PER BERONIUS
}

Division of Physical Chemistry, University of Umeå, S-901 87 Umeå, Sweden

Electrolytic conductance parameters according to the Fuoss-Hsia equation in the form of Fernandez-Prini and the less complete equation of Fuoss and Onsager have been used in analyzing, by means of the Acree equation, kinetic data for the exchange of halogen between alkyl halides and ionic 1:1-halides in methanol, aqueous ethanol, and acetone at $25^{\circ} \mathrm{C}$. The results suggest that the rate constant for the exchange reaction between alkyl halide and paired halide ions is underestimated if conductance parameters according to the Fuoss-Onsager relation are used. This effect is especially pronounced when association to ion-pairs is only slight. The choice between the two different conductance equations in evaluating the rate constant for the corresponding reaction involving unpaired halide ions is, however, immaterial.

The parameters derived from the more com. plete conductance equation are discussed in terms of Bjerrum's theory for ion association.

One problem encountered in interpreting kinetic data for ion-molecule reactions in solvent media where the ionic reactant associates to ion-pairs is to determine with sufficient accuracy, e.g. from electrical conductance data, the extent of ion-pair formation. The purpose of the present article is to discuss kinetic data for a few reactions of this kind in the light of recent progress in the theory of electrolytic conductance; $c f$. Refs. $1-9$.

The halogen exchange reactions ${ }^{10-12}$ to be discussed, see Table 3, were selected to cover a range of association constants for the ionic reactant. The association constants vary from $K_{\mathrm{A}} \simeq 10$ to $500 \mathrm{M}^{-1}$.

\section{CONDUCTANCE EQUATIONS}

For an 1:1-electrolyte which is subject to ionpair formation the degree of dissociation, $\alpha$, may be iteratively calculated from the set of equations,

$\alpha=\Lambda / \Lambda_{\mathrm{c}}$

$K_{\mathrm{A}}=(1-\alpha) / c \gamma^{2} \alpha^{2}$

$\log \gamma \simeq-A(c \alpha)^{\frac{1}{2}} /\left[1+B R(c \alpha)^{\frac{1}{2}}\right]$

where $\Lambda=$ molar conductivity at the stoichiometric concentration, $c ; \Lambda_{\mathrm{c}}=$ molar conductivity of the hypothetical completely dissociated electrolyte; $\gamma=$ mean molar activity coefficient of the dissociated electrolyte; $A$ and $B$ are functions ${ }^{13}$ of the permittivity, $\varepsilon$, of the solvent and the absolute temperature, $T$. The parameter $R$, the so-called association distance, is defined ${ }^{5-9}$ as the closest distance of approach of free ions (equivalent to the furthest distance of separation of the ions in the ion-pair).

For approximately the past 15 years the Fuoss-Onsager conductance equation, ${ }^{14-15}$ (FO equation),

$\Lambda_{\mathrm{c}}=\Lambda_{\infty}-S(c \alpha)^{\frac{1}{2}}+E c \alpha \log (c \alpha)+J c \alpha$

has been one of the more frequently employed reference functions to represent the conductance of the hypothetical completely dissociated electrolyte. Within the last few years the use of a more complete conductance equation according to Fuoss and Hsia ${ }^{1,2}$ in the form of FernandezPrini (FHFP equation),

$\Lambda_{\mathrm{c}}=\Lambda_{\infty}-S(c \alpha)^{\frac{1}{2}}+E c \alpha \log (c \alpha)+J_{1} c \alpha-J_{2}(c \alpha)^{3 / 2}$ 
has been discussed in a number of publications, e.g. in Refs. 5-9. The parameters of this equation are explained below.

It has been shown by DeRossi et al. ${ }^{8}$ among others, that omission of the $J_{2}(c \alpha)^{3 / 2}$ term introduces errors in $K_{\mathrm{A}}$ and $R$ which are not negligible. In fact, electrolytes classified ${ }^{16}$ as completely dissociated according to eqn. (4) appear to be weak when treated ${ }^{5}$ by means of eqn. (5).

A further recent development ${ }^{17}$ of the conductance theory, which takes into account the influence of the relaxation field on the electrophoretic effect ("Chen effect"), should be mentioned. Consideration of this effect changes the coefficients, $E, J_{1}$, and $J_{2}$ in eqn. (5) according to Ref. 9. However, the discrepancy between values of $K_{\mathrm{A}}$ and $R$ derived from the FHFP equation and the conductance equation modified with respect to the Chen effect does not exceed the experimental error for several electrolytic systems examined by DeRossi et al. ${ }^{8}$ and by Barthel et al., ${ }^{2}$ see Tables III and IV in Ref. 8 and Table 2 in Ref. 9. Hence, the Chen effect is not considered in the present study.

Evaluation of conductance parameters. The coefficients $J_{1}$ and $J_{2}$ in the FHFP equation are defined ${ }^{4}$ by the following equations:

$J_{1}=\sigma_{1} \Lambda_{\infty}+\sigma_{2}$

$J_{2}=\sigma_{3} \Lambda_{\infty}+\sigma_{4}$

$\sigma_{1}=\frac{x^{2} R^{2} b^{2}}{24 c \alpha}\left(1.8147+2 \ln \frac{x R}{(c \alpha)^{\frac{1}{2}}}+\frac{2\left(2 b^{2}+2 b-1\right)}{b^{3}}\right)$

$\sigma_{2}=B_{1} B_{2}+\frac{B_{2} \varkappa R}{(c \alpha)^{\frac{1}{2}}}-\frac{B_{2} \varkappa R b}{16(c \alpha)^{\frac{1}{2}}}\left(1.5337+\frac{4}{3 b}+\right.$

$\left.+2 \ln \frac{x R}{(c \alpha)^{\frac{1}{2}}}\right)$

$\sigma_{3}=\frac{b^{2} x^{3} R^{3}}{24(c \alpha)^{3 / 2}}\left(0.6094+\frac{4.4748}{b}+\frac{3.8284}{b^{2}}\right)$

$\sigma_{4}=\frac{B_{2} \varkappa^{2} R^{2} b^{2}}{24 c \alpha}\left(\frac{2\left(2 b^{2}+2 b-1\right)}{b^{3}}-1.9384\right)+$

$+\frac{B_{1} B_{2} \varkappa R}{(c \alpha)^{\frac{1}{3}}}+\frac{B_{2} \varkappa^{2} R^{2}}{c \alpha}-\frac{B_{2} b \varkappa^{2} R^{2}}{16 c \alpha}(1.5405+$

$\left.+\frac{2.2761}{b}\right)-\frac{B_{2}^{2} \varkappa R b}{16 \Lambda_{\infty}(c \alpha)^{\frac{1}{2}}}\left(\frac{4}{3 b}-2.2194\right)$

The coefficients $B_{1}$ and $B_{2}$, the electrophoretic and relaxation coefficients of the limiting law, and $\varkappa$, the Debye parameter, are defined in a monograph; $;^{15} \quad b=\left|z_{+} z_{-}\right| \mathrm{e}^{2} / \varepsilon \mathbf{k} T R$ where $z_{+}$and $z_{-}$are the valencies of the ions, $e=$ elementary charge, and $\mathbf{k}=$ Boltzmann's constant.

Combination of eqns. (1), (2), and (5) yields the following expression,

$\Lambda=\Lambda_{\infty}-S(c \alpha)^{\frac{1}{2}}+E c \alpha \log (c \alpha)+J_{1} c \alpha-J_{2}(c \alpha)^{3 / 2}-$
$-K_{\mathrm{A}} c \alpha \gamma^{2} \Lambda$

Starting with preliminary values for $\Lambda_{\infty}$ and $K_{\mathrm{A}}$ obtained from the $\mathrm{FO}$ equation by means of the computer program described in Ref. 18, the corresponding parameters according to the FHFP equation were calculated by numerical compensation.

Using a pre-selected value for $R$ and the preliminary figure for $\Lambda_{\infty}, \alpha$-values were iteratively calculated from eqns. (1) and (5) for all the experimental points, $c_{\mathfrak{i}} / \Lambda_{\mathrm{i}}, c f$. Ref. 12. The differences, $\Delta \Lambda_{\mathrm{i}}$, between the experimental molar conductivities and the corresponding quantities obtained from eqn. (9) were then established. Successive improvements of $\Lambda_{\infty}$ and $K_{\mathrm{A}}$ were obtained by additions of $\Delta \Lambda_{\infty}$ 's and $\Delta K_{\mathrm{A}}$ 's obtained from the equations,

$\Delta \Lambda_{\infty} \sum_{i=1}^{N}\left(\frac{\partial \Lambda}{\partial \Lambda_{\infty}}\right)_{i}^{2}+\Delta K_{\mathrm{A}} \sum_{\mathrm{i}}\left(\frac{\partial \Lambda}{\partial \Lambda_{\infty}}\right)_{i}\left(\frac{\partial \Lambda}{\partial K_{\mathrm{A}}}\right)_{\mathrm{i}}=$
$\sum_{\mathbf{i}}\left(\frac{\partial \Lambda}{\partial \Lambda_{\infty}}\right)_{\mathrm{i}} \Delta \Lambda_{\mathrm{i}}$

$\Delta \Lambda_{\infty} \sum_{i=1}^{N}\left(\frac{\partial \Lambda}{\partial K_{\mathrm{A}}}\right)_{\mathrm{i}}\left(\frac{\partial \Lambda}{\partial \Lambda_{\infty}}\right)_{\mathrm{i}}+\Delta K_{\mathrm{A}} \sum_{\mathrm{i}}\left(\frac{\partial \Lambda}{\partial K_{\mathrm{A}}}\right)_{\mathrm{i}}^{2}=$

$\sum_{\mathbf{i}}\left(\frac{\partial \Lambda}{\partial K_{\mathrm{A}}}\right)_{\mathbf{i}} \Delta \Lambda_{\mathrm{i}}$

The calculations were discontinued when $\Delta \Lambda_{\infty}<1 \times 10^{-7}$. Finally the standard deviation in the single $\Lambda$-value was calculated from the $N$ values of the set using the expression,

$\sigma(\Lambda)=\left(\frac{\sum\left(\Delta \Lambda_{i}\right)^{2}}{N-3}\right)^{\frac{1}{2}}$

The calculations were repeated for a series of association distances between 1 and $25 \AA$ using $0.2 \AA$ increments in $R$ to investigate the de. pendence of $\sigma(\Lambda)$ on $R$. The reason for not adjusting simultaneously all three parameters, $\Lambda_{\infty}, K_{\mathrm{A}}$, and $R$, which yields one set of values corresponding to $\sigma(\Lambda)=$ minimum, cf. Ref. 19, is that different combinations of values for $\Lambda_{\infty}$, $K_{\mathrm{A}}$, and $R$ may provide almost equally good

Acta Chem. Scand. A 28 (1974) No. 1 


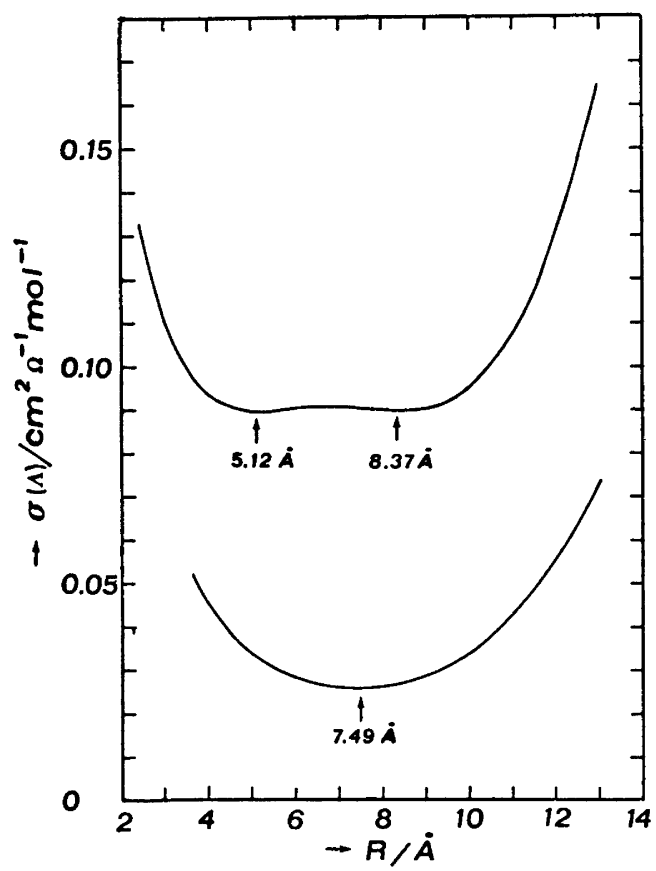

Fig. 1. Standard deviation of single $\Lambda$-value as a function of association distance. Upper curve derived from electrical conductance data in Ref. 18 for CsI in $\mathbf{C H}_{3} \mathrm{OH}$. Bottom curve calculated from data in Ref. 11 for $\mathrm{NaI}$ in $\mathrm{C}_{2} \mathrm{H}_{5} \mathrm{OH}$, 6.26 wt $-\% \mathrm{H}_{2} \mathrm{O}$ at $25^{\circ} \mathrm{C}$.

fits of the conductance equation to the experimental values as pointed out in Ref. 5 .

To illustrate this statement, $\sigma(\Lambda)$ for cesium iodide in methanol at $25^{\circ} \mathrm{C}$, calculated from the conductance data in Ref. 18, has been plotted vs. $R$ in Fig. 1 (upper curve). As can be seen two minima corresponding to nearly identical standard deviations appear. The minimum at $R=$ $5.12 \AA\left(\Lambda_{\infty}=124.13 ; K_{\mathrm{A}}=14.0\right)$ corresponds to $\sigma(\Lambda)=0.0897$ while the minimum at $R=8.37 \AA$ $\left(\Lambda_{\infty}=124.15 ; K_{\mathrm{A}}=23.7\right)$ corresponds to the insignificantly larger value, $\sigma(\Lambda)=0.0900$.

For comparison the bottom curve in Fig. 1 derived from conductance data in Ref. 11 for sodium iodide in aqueous ethanol at $25^{\circ} \mathrm{C}$ shows only one minimum.

After the main shape of the $\sigma(\Lambda)$ vs. $R$ curve (cf. Fig. 1) had been established, further calculations with successively decreasing increments in $R$ were performed near the minimum (or minima) to obtain the $R$-value for the latter to within $5 \times 10^{-3} \AA$.

Acta Chem. Scand. A 28 (1974) No. 1
Of the ten electrolytic systems examined, three systems, viz. cesium iodide in methanol, potassium iodide in aqueous ethanol, and tetrabutylammonium chloride in acetone yielded error curves with two minima (cf. upper curve in Fig. 1) while the remaining systems yielded curves with a single minimum.

Conductance parameters according to the FO equation were calculated using the computer program outlined in Ref. 18. This program, which operates essentially according to the method of Kay, ${ }^{19}$ involves iterative determinations of $\Lambda_{\infty}, K_{\mathrm{A}}$, and $R$ from the three normal equations derived from the expression,

$\Delta \Lambda=\frac{\partial \Lambda}{\partial \Lambda_{\infty}} \Delta \Lambda_{\infty}+\frac{\partial \Lambda}{\partial K_{\mathrm{A}}} \Delta K_{\mathrm{A}}+\frac{\partial \Lambda}{\partial R} \Delta R$

Accordingly, only one set of values for the quantities sought are obtained in this case.

\section{RESULTS AND DISCUSSION}

Conductance data. Conductance parameters derived from the FHFP equation for sodium, potassium, rubidium, and cesium iodides in methanol ${ }^{18}$ and aqueous ethanol,11 and for tetrabutylammonium chloride and bromide in acetone, ${ }^{12}$ are compared in Table 1 with the corresponding data obtained from the FO equation. This table also includes the permittivities ${ }^{11,20,21}$ and viscosities ${ }^{11,21,22}$ used in the calculations and Bjerrum's critical distance, ${ }^{23}$

$q=\left|z_{+} z_{-}\right| e^{2} / 2 \varepsilon \mathbf{k} T$

Two sets of values according to the FHFP equation are given for those three systems for which two minima appeared in the $\sigma(\Lambda)$ vs. $R$ curve ( $c f$. Fig. 1). The values corresponding to the minimum with the larger $\sigma(\Lambda)$ are given in brackets.

Comparison of the data listed in Table 1 for the FHFP and FO equations reveals a better fit of the FHFP equation to the experimental conductance data; see the $\sigma(\Lambda)$ 's given in the last column. The FHFP equation yields larger association constants and association distances than the FO equation. The discrepancy between the values of $K_{\mathrm{A}}$ for the two conductance equations concerned is especially pronounced when association to ion-pairs is only slight, see the data for sodium, potassium, and rubidium iodides in methanol. 
Table 1. Electrical conductance parameters according to the FHFP and FO equations at $25^{\circ} \mathrm{C}$.

\begin{tabular}{|c|c|c|c|c|c|}
\hline Electrolyte & Eqn. & $\begin{array}{l}\Lambda_{\infty} \\
\mathrm{cm}^{2} \Omega^{-1} \mathrm{~mol}^{-1}\end{array}$ & $\begin{array}{l}K_{\mathrm{A}} \\
\mathrm{A}^{-1}\end{array}$ & $\begin{array}{l}R \\
\AA\end{array}$ & $\begin{array}{l}\sigma(\Lambda) \\
\mathrm{cm}^{2} \Omega^{-1} \mathrm{~mol}^{-1}\end{array}$ \\
\hline & \multicolumn{5}{|c|}{$\begin{array}{l}\mathrm{CH}_{3} \mathrm{OH} ; \varepsilon=32.63 ; \eta=0.5445 \mathrm{cP} ; q=8.59 \AA ; \\
c, \Lambda \text {-values according to Table } 1, \text { Ref. } 18 .\end{array}$} \\
\hline \multirow{2}{*}{$\mathrm{NaI}$} & FHFP & 108.37 & 9.2 & 6.6 & 0.083 \\
\hline & $\mathrm{FO}$ & 108.38 & 2.2 & 4.3 & 0.084 \\
\hline \multirow[t]{2}{*}{ KI } & FHFP & 115.45 & 13.0 & 7.4 & 0.046 \\
\hline & FO & 115.43 & 2.3 & 4.0 & 0.053 \\
\hline \multirow[t]{2}{*}{ RbI } & FHFP & 119.62 & 17.1 & $\mathbf{7 . 4}$ & 0.067 \\
\hline & $\mathrm{FO}$ & 119.60 & 6.0 & 4.0 & 0.072 \\
\hline \multirow[t]{3}{*}{ CsI } & FHFP & 124.13 & 14.0 & 5.1 & 0.0897 \\
\hline & FO & $\begin{array}{l}(124.15) \\
124.12\end{array}$ & $\begin{array}{c}(23.7) \\
9.4\end{array}$ & $\begin{array}{c}(8.4) \\
3.8\end{array}$ & $\begin{array}{c}(0.0900) \\
0.0934\end{array}$ \\
\hline & \multicolumn{5}{|c|}{$\begin{array}{l}\mathrm{C}_{2} \mathrm{H}_{6} \mathrm{OH}, 6.26 \text { wt- } \% \mathrm{H}_{2} \mathrm{O} ; \varepsilon=27.1 ; \eta=1.329 \mathrm{cP} ; \\
q=10.34 \AA ; c, \Lambda \text {-values according to Table 2, Ref. } 11 .\end{array}$} \\
\hline \multirow{4}{*}{$\begin{array}{l}\mathrm{NaI} \\
\mathrm{KI}\end{array}$} & $\begin{array}{l}\text { FHFP } \\
\text { FO }\end{array}$ & $\begin{array}{l}46.81 \\
46.81\end{array}$ & $\begin{array}{l}26.7 \\
13.2\end{array}$ & $\begin{array}{l}7.5 \\
4.7\end{array}$ & 0.026 \\
\hline & FHFP & $\begin{array}{l}40.81 \\
49.80\end{array}$ & 25.7 & 5.2 & $\begin{array}{l}0.028 \\
0.020\end{array}$ \\
\hline & & $(49.84)$ & $(44.9)$ & $(9.0)$ & $(0.024)$ \\
\hline & FO & 49.79 & 18.9 & 4.0 & 0.020 \\
\hline \multirow{2}{*}{$\mathrm{RbI}$} & FHFP & 50.68 & 51.3 & 7.6 & 0.012 \\
\hline & & 50.65 & 34.4 & 4.4 & 0.015 \\
\hline \multirow{3}{*}{ CsI } & FHFP & 51.33 & 61.7 & 5.9 & 0.029 \\
\hline & FO & 51.31 & 52.2 & 4.3 & 0.031 \\
\hline & \multicolumn{5}{|c|}{$\begin{array}{l}\left(\mathrm{CH}_{3}\right)_{2} \mathrm{CO} ; \varepsilon=20.7 ; \eta=0.304 \mathrm{cP} ; q=13.54 \AA ; \\
c, \Lambda \text {-values according to Table } 1 \text {, Ref. } 12 .\end{array}$} \\
\hline \multirow{4}{*}{$\begin{array}{l}\left(\mathrm{C}_{4} \mathrm{H}_{9}\right)_{4} \mathrm{NBr} \\
\left(\mathrm{C}_{4} \mathrm{H}_{9}\right)_{4} \mathrm{NCl}\end{array}$} & FHFP & 187.09 & 363 & 11.6 & 0.237 \\
\hline & FO & 186.82 & 297 & 5.0 & 0.341 \\
\hline & FHFP & 187.88 & 466 & 6.2 & 0.167 \\
\hline & FO & $\begin{array}{l}188.03) \\
187.85\end{array}$ & $\begin{array}{c}(528) \\
453\end{array}$ & $\begin{array}{c}(13.6) \\
5.1\end{array}$ & $\begin{array}{c}(0.178) \\
0.192\end{array}$ \\
\hline
\end{tabular}

Table 2. Comparisons of the association distance, $R$, according to the FHFP equation at $25^{\circ} \mathrm{C}$ with Bjerrum's critical distance, $q$, and of the closest distance of approach of the ions, $a_{\mathrm{K}}{ }^{\mathrm{B}}$, according to Bjerrum's equation with the crystal radii sum, $r_{+}+r_{-}$.

\begin{tabular}{|c|c|c|c|c|c|}
\hline Electrolyte & $\underset{\mathbf{M}^{-1}}{K_{\mathrm{A}}}$ & $\stackrel{R}{\AA}$ & $\begin{array}{l}q \\
\AA\end{array}$ & $\stackrel{\mathrm{K}}{\mathrm{K}}^{\mathrm{B}}$ & $\stackrel{r}{+}^{+}+r_{-}$ \\
\hline $\begin{array}{l}\mathrm{NaI} \\
\mathrm{KI} \\
\mathrm{RbI} \\
\mathrm{CsI}\end{array}$ & $\begin{array}{r}\mathrm{CH}_{3} \mathrm{O} \\
9.2 \\
13.0 \\
17.1 \\
14.0 \\
(23.7)\end{array}$ & $\begin{array}{c}6.6 \\
7.4 \\
7.4 \\
5.1 \\
(8.4)\end{array}$ & $\begin{array}{l}8.6 \\
8.6 \\
8.6 \\
8.6 \\
8.6\end{array}$ & $\begin{array}{c}6.4 \\
5.6 \\
4.9 \\
5.4 \\
(4.0)\end{array}$ & $\begin{array}{l}3.1 \\
3.5 \\
3.6 \\
3.9 \\
3.9\end{array}$ \\
\hline $\begin{array}{l}\mathrm{NaI} \\
\mathrm{KI} \\
\mathrm{RbI} \\
\mathrm{CsI}\end{array}$ & $\begin{array}{c}\mathrm{C}_{2} \mathrm{H}_{5} \\
26.7 \\
25.7 \\
(44.9) \\
51.3 \\
61.7\end{array}$ & $\begin{array}{r}\text { vt. } \% \text { I } \\
7.5 \\
5.2 \\
(9.0) \\
7.6 \\
5.9\end{array}$ & $\begin{array}{l}10.3 \\
10.3 \\
10.3 \\
10.3 \\
10.3\end{array}$ & $\begin{array}{c}6.2 \\
6.4 \\
(4.5) \\
4.2 \\
3.7\end{array}$ & $\begin{array}{l}3.1 \\
3.5 \\
3.5 \\
3.6 \\
3.9\end{array}$ \\
\hline $\begin{array}{l}\left(\mathrm{C}_{4} \mathrm{H}_{9}\right)_{4} \mathrm{NBr} \\
\left(\mathrm{C}_{4} \mathrm{H}_{9}\right)_{4} \mathrm{NCl}\end{array}$ & $\begin{array}{c}\left(\mathrm{CH}_{3}\right) \\
363 \\
466 \\
(528)\end{array}$ & $\begin{array}{r}11.6 \\
6.2 \\
(13.6)\end{array}$ & $\begin{array}{l}13.5 \\
13.5 \\
13.5\end{array}$ & $\begin{array}{c}3.2 \\
3.0 \\
(2.9)\end{array}$ & $\begin{array}{l}6.9 \\
6.8 \\
6.8\end{array}$ \\
\hline
\end{tabular}


Table 3. Acree equation rate constants obtained on the basis of electrical conductance parameters according to the FHFP and $\mathrm{FO}$ equations at $25^{\circ} \mathrm{C}$.

\begin{tabular}{|c|c|c|c|}
\hline Reactants & $\begin{array}{l}\text { Cond. } \\
\text { eqn. }\end{array}$ & $\begin{array}{l}k_{\mathrm{i}} \times 10^{3} \\
\mathrm{M}^{-1} \mathrm{~s}^{-1}\end{array}$ & $\begin{array}{l}k_{\mathrm{m}} \times 10^{3} \\
\mathrm{M}^{-1} \mathrm{~s}^{-1}\end{array}$ \\
\hline \multirow{5}{*}{$\begin{array}{l}\mathrm{Na}^{131} \mathrm{I}+\mathrm{CH}_{3} \mathrm{I} \\
\mathrm{K}^{131} \mathrm{I}+\mathrm{CH}_{3} \mathrm{I}\end{array}$} & \multicolumn{3}{|l|}{$\mathrm{CH}_{3} \mathrm{OH}$} \\
\hline & FHFP & $3.319 \pm 0.018$ & \multirow{8}{*}{$\begin{array}{r}0.58 \pm 0.90 \\
-8.2 \pm 3.9 \\
0.35 \pm 1.11 \\
-13.7 \pm 6.5 \\
1.61 \pm 0.44 \\
-1.54 \pm 1.27 \\
1.11 \pm 0.71 \\
(2.02 \pm 0.41) \\
0.03 \pm 1.07\end{array}$} \\
\hline & & $3.320 \pm 0.018$ & \\
\hline & FHFP & $3.332 \pm 0.031$ & \\
\hline & & $3.332 \pm 0.031$ & \\
\hline $\mathrm{Rb}^{131} \mathrm{I}+\mathrm{CH}_{3} \mathrm{I}$ & FHFP & $3.309 \pm 0.016$ & \\
\hline & FO & $3.309 \pm 0.016$ & \\
\hline \multirow[t]{2}{*}{$\mathrm{Cs}^{131} \mathrm{I}+\mathrm{CH}_{3} \mathrm{I}$} & FHFP & $\begin{array}{r}3.301 \pm 0.020 \\
(3.301 \pm 0.020)\end{array}$ & \\
\hline & FO & $3.301 \pm 0.020$ & \\
\hline \multirow{3}{*}{$\mathrm{Na}^{131} \mathrm{I}+\mathrm{CH}_{3} \mathrm{I}$} & \multicolumn{3}{|c|}{$\mathrm{C}_{2} \mathrm{H}_{5} \mathrm{OH}, 6.26$ wt- $\% \mathrm{H}_{2} \mathrm{O}$} \\
\hline & \multirow{3}{*}{$\begin{array}{l}\text { FHFP } \\
\text { FO } \\
\text { FHFP }\end{array}$} & $10.72 \pm 0.029$ & \multirow{8}{*}{$\begin{array}{r}3.92 \pm 0.60 \\
-3.07 \pm 1.26 \\
-2.95 \pm 0.72 \\
(2.81 \pm 0.40) \\
-7.90 \pm 0.97 \\
2.42 \pm 0.32 \\
-1.58 \pm 0.50 \\
2.58 \pm 0.44 \\
1.14 \pm 0.52\end{array}$} \\
\hline & & $10.72 \pm 0.029$ & \\
\hline $\mathrm{K}^{131} \mathrm{I}+\mathrm{CH}_{3} \mathrm{I}$ & & $\begin{array}{c}10.70 \pm 0.032 \\
(10.70 \pm 0.032)\end{array}$ & \\
\hline \multirow{3}{*}{$\mathrm{Rb}^{131} \mathrm{I}+\mathrm{CH}_{3} \mathrm{I}$} & FO & $10.70 \pm 0.031$ & \\
\hline & FHFP & $10.69 \pm 0.028$ & \\
\hline & FO & $10.69 \pm 0.028$ & \\
\hline \multirow{2}{*}{$\mathrm{Cs}^{131} \mathrm{I}+\mathrm{CH}_{3} \mathrm{I}$} & FHFP & $10.75 \mp 0.030$ & \\
\hline & FO & $10.75 \pm 0.030$ & \\
\hline \multirow{5}{*}{$\begin{array}{l}\left(\mathrm{C}_{6} \mathrm{H}_{8}\right)_{4} \mathrm{~N}^{82} \mathrm{Br}+ \\
\mathrm{C}_{4} \mathrm{H}_{8} \mathrm{Br} \\
\left(\mathrm{C}_{4} \mathrm{H}_{8}\right)_{4} \mathrm{~N}^{36} \mathrm{Cl}+ \\
p-\mathrm{NO}_{2} \mathrm{C}_{6} \mathrm{H}_{4} \mathrm{CH}_{2} \mathrm{Cl}\end{array}$} & $\left(\mathrm{CH}_{3}\right)_{2} \mathrm{CC}$ & & \multirow{5}{*}{$\begin{array}{c}1.92 \pm 0.08 \\
0.86 \pm 0.11 \\
2.68 \pm 0.37 \\
(6.10 \pm 0.31) \\
1.82 \pm 0.39\end{array}$} \\
\hline & FHFP & $7.041 \pm 0.041$ & \\
\hline & FO & $7.043 \pm 0.041$ & \\
\hline & FHFP & $\begin{array}{c}34.20 \pm 0.15 \\
(34.22 \pm 0.15)\end{array}$ & \\
\hline & FO & $34.21 \pm 0.15$ & \\
\hline
\end{tabular}

Justice ${ }^{7}$ has suggested that the association distance, $R$, should be identified with Bjerrum's critical distance, $q$. Values for these parameters are compared in Table 2 from which it may be seen that the association distances derived from the FHFP equation are generally a little less than Bjerrum's critical distance.

In Table 2 comparison is also made between the crystal radii ${ }^{24}$ sum, $r_{+}+r_{-}$, and the distance of closest approach, $a_{\mathrm{K}}{ }^{\mathrm{B}}$, of the ions as derived from Bjerrum's equation, ${ }^{23}$

$$
K_{\mathrm{A}}=\frac{4 \pi N}{1000} \int_{a_{\mathrm{K}}^{\mathrm{B}}}^{q} r^{2} \exp \left(\frac{\left|z_{+} z_{-}\right| e^{2}}{\varepsilon \mathbf{k} T r}\right) d r
$$

For the alcoholic solvents the distance of closest approach derived from eqn. (14) shows a tendency to increase with decreasing size of the cation, which may be attributed to solvation phenomena. For acetone as solvent the unsatisfactory result, $a_{\mathrm{K}}{ }^{\mathrm{B}}<r_{+}+r_{-}$, is obtained.

Kinetic data. The exchange reactions examined, which may be symbolized by the general formula,

$\mathrm{RY}+\mathrm{AY}^{*} \stackrel{k}{\rightleftharpoons} \mathrm{RY}^{*}+\mathrm{AY}$

where RY is an alkyl halide, AY an ionic halide, and where the asterisks indicate radioactive atoms ${ }^{(38} \mathrm{Cl},{ }^{82} \mathrm{Br}$, or $\left.{ }^{131} \mathrm{I}\right)$, are listed in Table 3.

The primary kinetic data, viz. overall secondorder rate constants, $k$, at several different concentrations of the ionic reactant, were taken from Table I in Ref. 10, Table 1 in Ref. 11, and from Tables 2 and 3 in Ref. 12.

The separated rate constants, $k_{\mathrm{i}}$ and $k_{\mathrm{m}}$, for the two exchange reactions,

Acta Chem. Scand. A 28 (1974) No. 1 


$$
\begin{aligned}
& \mathrm{RY}+\mathrm{Y}^{*-} \stackrel{k_{\mathrm{i}}}{\rightleftharpoons} \mathrm{RY}^{*}+\mathrm{Y}^{-} \\
& \mathrm{RY}+\mathrm{A}^{+} \mathrm{Y}^{*-} \stackrel{k_{\mathrm{m}}}{\rightleftharpoons} \mathrm{RY} \mathrm{Y}^{*}+\mathrm{A}^{+} \mathrm{Y}^{-}
\end{aligned}
$$

involving unpaired and paired halide ions, $\mathrm{Y}^{-}$ and $\mathrm{A}^{+} \mathrm{Y}^{-}$, respectively, were evaluated from the Acree equation,

$k / \alpha=k_{\mathrm{i}}+k_{\mathrm{m}}(1-\alpha) / \alpha$

using the method of least squares.

The results of these calculations are listed in columns 3 and 4 of Table 3. The errors quoted are standard deviations. Values given in brackets are rate constants corresponding to the bracketed association constants and association distances in Table 1.

Table 3 reveals that the rate constant, $k_{\mathrm{i}}$, calculated on the basis of $K_{\mathrm{A}}$ - and $R$-values derived from the two different conductance equations discussed, are almost identical. This is not so for the corresponding rate constants, $k_{\mathrm{m}}$, for the reaction between alkyl halide and paired halide ions. Values of $k_{\mathrm{m}}$ derived using conductance parameters from the FHFP equation are significantly larger than the $k_{\mathrm{m}}$ 's based on the FO equation.

For six of the systems listed in Table 3 the rate constant, $k_{\mathrm{m}}$, based on the FO equation exhibits physically impossible negative values. It may be noted as an encouraging fact that the $k_{\mathrm{m}}$ 's derived using association constants and association distances from the FHFP equation are no longer negative, disregarding one of the values for the reaction between potassium iodide and methyl iodide in aqueous ethanol.

From Table 3 it may also be concluded that the choice between the two conductance equations concerned, with respect to the evaluation of the rate constant, $k_{\mathrm{m}}$, becomes less important with increasing $K_{\mathrm{A}}$-value. For example the large discrepancy between the $k_{\mathrm{m}}$-values $0.6 \times 10^{-3}$ and $-8.2 \times 10^{-3} \mathrm{M}^{-1} \mathrm{~s}^{-1}$ according to the FHFP and $\mathrm{FO}$ equations for the reaction involving sodium iodide and methyl iodide in methanol $\left(K_{\mathrm{A}}=9.2\right.$ and $2.2 \mathrm{M}^{-1}$, respectively) may be compared with the considerably smaller deviation between the corresponding $k_{\mathrm{m}}$-values $1.9 \times 10^{-3}$ and $0.9 \times 10^{-3} \mathrm{M}^{-1} \mathrm{~s}^{-1}$ for the reaction between tetrabutylammonium bromide and butyl bromide in acetone $\left(K_{\mathrm{A}}=363\right.$ and 297 $\mathbf{M}^{-1}$, respectively).
Acknowledgement. The financial support from the Swedish Natural Science Research Council is gratefully acknowledged.

\section{REFERENCES}

1. Fuoss, R. M. and Hsia, K.-L. Proc. Nat. Acad. Sci. U.S. 57 (1967) 1550.

2. Fuoss, R. M. and Hsia, K.-L. Proc. Nat. Acad. Sci. U.S. 58 (1968) 1818.

3. Fernandez-Prini, R. Trans. Faraday Soc. 64 (1968) 2146.

4. Fernandez-Prini, R. Trans. Faraday Soc. 65 (1969) 3311.

5. Hanna, E. M., Pethybridge, A. D. and Prue, J. E. J. Phys. Chem. 75 (1971) 291.

6. Hanna, E. M., Pethybridge, A. D. and Prue, J. E. Electrochim. Acta 16 (1971) 677.

7. Justice, J.-C. Electrochim. Acta 16 (1971) 701 .

8. DeRossi, C., Sesta, B., Battistini, M. and Petrucci, S. J. Amer. Chem. Soc. 94 (1972) 2961.

9. Barthel, J., Justice, J.-C. and Wachter, R. Z. Physik. Chem. (Frankfurt am Main) 84 (1973) 100

10. Beronius, P. and Pataki, L. J. Amer. Chem. Soc. 92 (1970) 4518.

11. Beronius, P. and Pataki, L. Acta Chem. Scand. 25 (1971) 3705.

12. Beronius, P., Nilsson, A.-M. and Wikander, G. Acta Chem. Scand. 24 (1970) 2826.

13. Robinson, R. A. and Stokes, R. H. Electrolyte Solutions, Butterworths, London 1965 , p. 230.

14. Fuoss, R. M. and Onsager, L. J. Phys. Chem. 61 (1957) 668.

15. Fuoss, R. M. and Accascina, F. Electrolytic Conductance, Interscience, New York 1959.

16. Atkinson, G. and Petrucci, S. J. Phys. Chem. 67 (1963) 1880.

17. Chen, M. S. Thesis, Yale University 1969

18. Beronius, P., Wikander, G. and Nilsson, A.M. Z. Physik. Chem. (Frankfurt am Main) 70 (1970) 52.

19. Kay, R. L. J. Amer. Chem. Soc. 82 (1960) 2099.

20. Weast, R. C., Ed., Handbook of Chemistry and Physics, 52nd Ed., The Chemical Rubber Co., Cleveland, Ohio, 1971-1972, E44.

21. Nilsson, A.-M. and Beronius, P. Z. Physik. Chem. (Frankfurt am Main) 79 (1972) 83.

22. Weissberger, A., Ed., Technique of Organic Chemistry, 2nd Ed., Interscience, New York 1955, Vol. VII, p. 90.

23. Bjerrum, N. Kgl. Dan. Vidensk. Selsk. 7 (1926) No. 9.

24. Robinson, R. A. and Stokes, R. H. Electrolyte Solutions, Butterworths, London 1965, pp. 125 and 461 .

Received July 17, 1973.

Acta Chem. Scand. A 28 (1974) No. 1 